\title{
Perfil sociodemográfico de Tehuacán durante el virreinato
}

\author{
-Agustín Grajales Porras \\ José Luis Aranda Romero*
}

El artículo ofrece un panorama geohistórico de la región de Tehuacán, valle tan rico en recursos naturales que propició el desarrollo de culturas con una antigüedad hasta de diez milenios y que desde los tiempos prehispánicos ha fungido como enlace comercial entre el altiplano y el sureste mesoamericano. En la actualidad, el distrito se erige como el centro económico, político y cultural más importante del sur del estado de Pueblo. En este trabajo se reconstruyen las transformaciones que sufrió en su división territorial, así como su papel en la conformación político-administrativa del obispado, la intendencia y finalmente el estado de la República. El artículo también presenta un bosquejo de la evolución de la población desde los tiempos remotos hasta las postrimerías del régimen colonial. Los datos utilizados van desde recuentos primigenios de tributarios y familias indígenas, con los que se muestra la implosión demográfica que experimentó la ooblación novohispana a lo largo del siglo XVI, y su recuperación a partir de la segunda mitad del siglo siguiente, hasta el padrón militar que se levantó en el año 1791. Este último permite - a doscientos años de su elaboración- delinear el orden demográfico y social de la ciudad de Tehuacán de las Granadas.

En la víspera del contacto entre el mundo europeo y el mesoamericano, el valle de Tehuacán y su contorno se encontraban sometidos política y culturalmente a Tenochtitlan; Coxcatlán, situada al sureste de la región, se erguía como el asentamiento más importante. La ciudad de Tehuacán fue un establecimiento fundado posteriormente -en el periodo de acomodamiento del sistema colonial-cuyas raíces se remontan a la antigua Coapan, emplazada media legua al noreste de su posición actual. En medio de la política de redistribución de la población indígena que se practicó desde el temprano régimen colonial, los franciscanos, en 1538, trasladaron el asentamiento prehispánico al sitio denominado Calcahual-

* Instituto de Ciencias Sociales y Humanidades, Universidad Autónoma de Puebla. Los autores agradecen a Jesús Barbosa Ramírez y Andrés Hernández Vásquez, pasantes del Colegio de Historia de la Escuela de Filosofía y Letras de la UAP, su asistencia en el rescate de la información proveniente del padrón militar de la jurisdicción de Tehuacán. 
co. A la postre, los naturales abandonaron el paraje "por ser propenso a fríos y calenturas", ya que era "tierra baja, húmeda, mal ventilada y muy caliente". En 1567, a petición de sus mismos fundadores, Tehuacán, establecida a una legua del punto anterior, formaliza su fundación como "ciudad de yndios", con licencia del virrey Marqués de Falces. Según asienta Torquemada, los primeros pobladores eligieron un sitio "templadísimo, muy airoso y de buena tierra, donde hoy día se hacen las mejores uvas, granadas, [y] membrillos que hay en Nueva España..." Por Real Cédula de primero de junio de 1654 se le concede título de ciudad con privilegios iguales a los de Tlaxcala; merced a la lealtad que mostraron sus antepasados a la Corona desde el primer encuentro, cuando los caciques se sujetaron de buena voluntad a las armas castellanas, a pesar de que el valle "pertenecía al Grande Moctezuma". Seis años más tarde, precisamente el 16 de marzo de 1660 , se le otorga escudo de armas, bajo la gestión del duque de Alburquerque. ${ }^{1}$

Hacia 1550, Tehuacán aparece ya como una población de importancia en una relación de los límites del obispado de Tlaxcala; cuya iglesia catedral, obispo, deán y cabildo, debían residir en la ciudad de Puebla de los Ángeles. En cumplimiento de una cédula real, el virrey don Antonio de Mendoza ejecutó la merced de 15 leguas en vía recta desde los diversos distritos aledaños a la ciudad episcopal. De esta manera, los pueblos de "Teguacán" (no a 15 , sino a 17 leguas) y de "Cuscatlán" pasaron a formar parte del primitivo obispado de Tlaxcala. ${ }^{2}$ A fines del siglo XVI, según la descripción geográfica del distrito del obispado de Tlaxcala, se mencionan como territorio del obispado -aparte de "Teguacán" (perteneciente a la Corona real y bajo la doctrina de frailes franciscanos) y de "Cuzcatlán" (de la Corona y beneficio de clérigo)- los pueblos cabeceras de "Chiapulco" (encomienda de Esteban de Carbajal, de frailes franciscanos), Zapotitlán (de Gaspar de Garnica y de Cristóbal Montaño, beneficio de clérigo), Zoquitlán (encomienda de Diego de Montalvo, del dicho beneficio de "Cuzcatlán") y Elosuchitlán (de doña Luisa de Frías, del mismo beneficio) (A. Commons, 1971: 36-39).

El cosmógrafo fray Antonio Vázquez de Espinosa, en su Compendio y Descripción de las Indias Occidentales, señala a Tehuacán como Alcaldía Mayor del Obispado de Puebla en la Audiencia

\footnotetext{
${ }^{1}$ Véanse don Vicente Nieto; A. Commons de la Rosẩ (1971:59) y Enrique Juan Palacios (1982: 288-289).

2 AG.., Hamo Mercedes, t. 3, ff. 159-163; citado por A. Commons (1971: 30-36).
} 
de México y a Coxcatlán como corregimiento, a principios del siglo XVII. Para entonces el obispado contaba con 15 alcaldías y 20 corregimientos. Para resaltar la importancia que tenía ya Tehuacán en el territorio episcopal, se debe mencionar que ciudades como Cholula, "Guajozingo", Veracruz Nueva, San Juan de los Llanos y la Villa de Orizaba eran sólo corregimientos (A. Commons, 1971:40). A mediados del mismo siglo comprendía - según relata el cosmógrafo de México Joseph Antonio de Villaseñor y Sánchez, en su Theatro Americano- la propia ciudad cabecera de Tehuacán de las Granadas y nueve pueblos principales: San Gabriel Chilac, San Miguel Elosuchitlán, San Martín Mazateopan, San Pedro Teltitlán, San Pedro Chapulco, Coxcatlán, Acatepec, San Pablo Zoquitlán y Santa María Coyomeapa (A. Commons, 1971:46).

La calidad de Alcaldía Mayor de la cabecera de la jurisdicción se conservó aún en 1786, cuando se reestructuró la organización político-administrativa de la Nueva España borbónica - según el modelo francés- bajo el virreinato de Bernardo de Gálvez. Hacia la última década del siglo XVIII, la provincia de Tehuacán, perteneciente a la nueva Intendencia de Puebla, tenía una gran extensión: estaba situada entre los paralelos de $17^{\circ} 40^{\prime}$ y de $19^{\circ} 4^{\prime}$ de latitud y entre $276^{\circ} 15^{\prime}$, y $278^{\circ} 7^{\prime}$ de longitud del meridiano de Tenerife; sus términos comprendían de norte a sur 28 leguas y 36 , de oriente a poniente. Su capital distaba 43 leguas de la ciudad de México y 25 de la ciudad de Puebla (distancia ocho leguas mayor que la medición en línea recta de mediados del siglo XVI, señalada anteriormente; la diferencia podría atribuirse a que el seguimiento en el trazo fue diferente, ya que ahora debió serpentear el camino real de México a Puebla y Oaxaca, que cruzaba la ciudad de Tehuacán). El territorio confinaba al norte con Orizaba y la Antigua, hacia el sur con Teposcolula, al este con Veracruz Nueva y al oeste con Tepexi de la Seda; por el noroeste con Tepeaca, al suroeste con Huajuapan; por el sureste con Teotitlán y Teutila y por el noreste con Córdoba (véase Vicente Nieto, 1791: ff. 1-1v).

Los partidos que conformaban su territorio eran Tehuacán de las Granadas, Chapulco, Tepanco, Coxcatlán, La Cañada, Zapotitlán y Zoquitlán (véase mapa). El partido de la cabecera de la jurisdicción abarcaba los pueblos de San Lorenzo, Santa María Coapa, San Marcos, Santa Cruz, San Pablo Tepetzingo y San Diego; las haciendas de San Lorenzo, El Riego, El Humilladero, Santa Cruz, La Huerta, San Andrés y Chapultepeque; el rancho de los Méndez y los molinos de Santa Cruz, Calcahualco y el Molino Chico.

La cabecera de San Pedro Chapulco se acompañaba de los pueblos de Santiago Miahuatlán y de Santa María Magdalena; de las haciendas del Carnero, de San Francisco Xavier, alias La Com- 


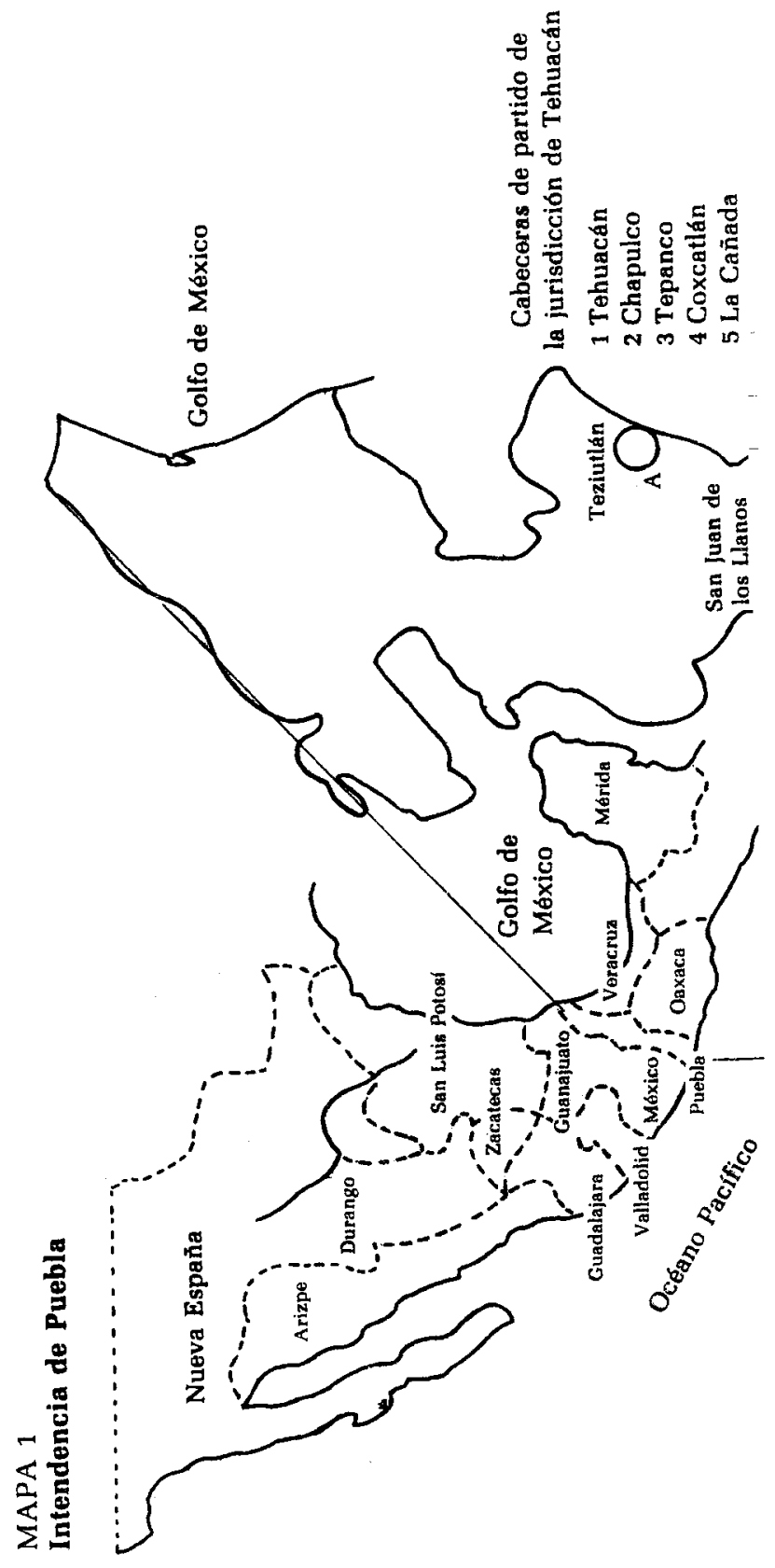




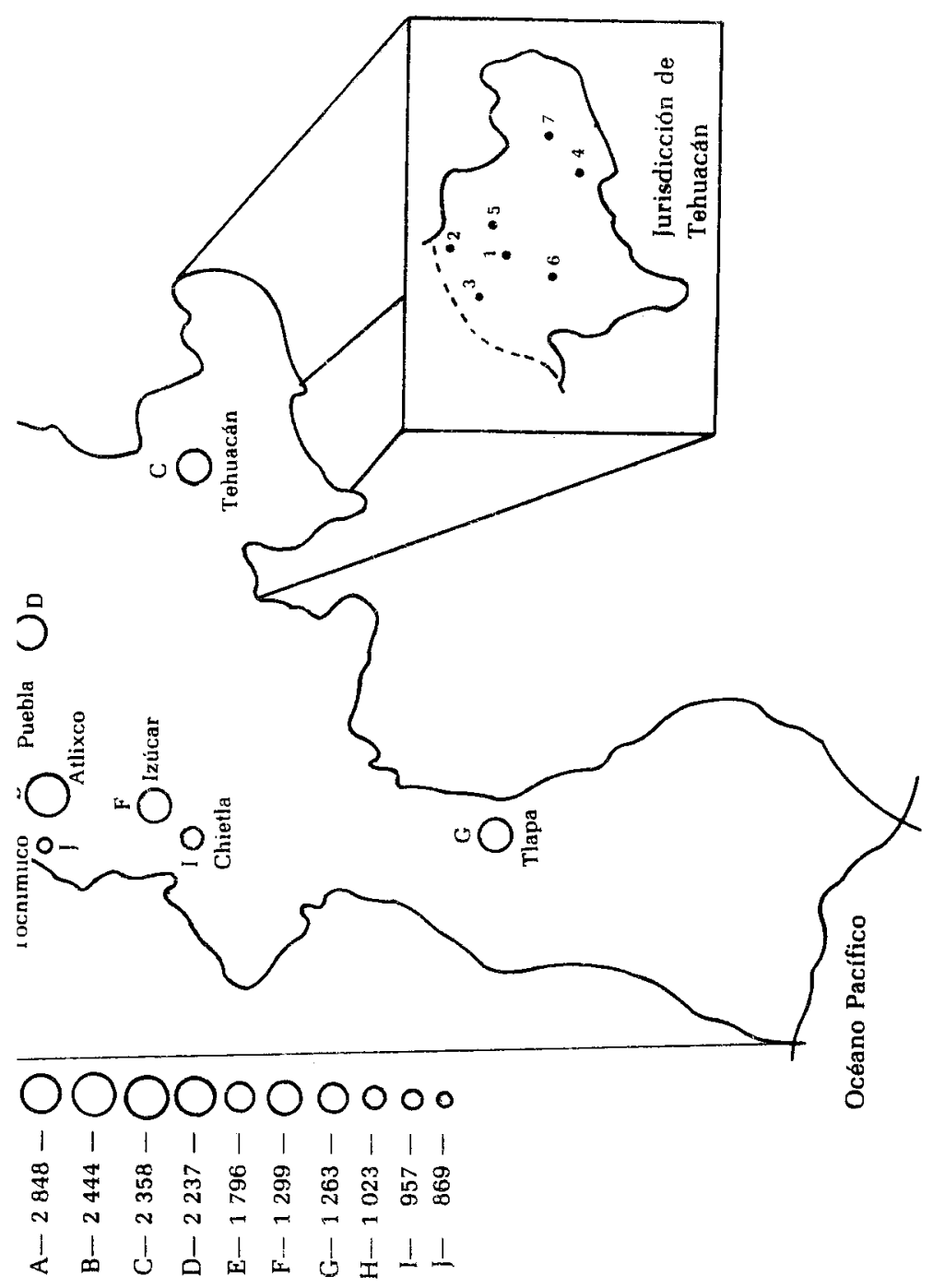


pañía, y la de San Andrés; de los ranchos de Tecajete y San Felipe; así como las rancherías de San Antonio, San Felipe e Ixtle.

El pueblo de San Juan Tepanco, cabecera de su partido, sólo incluía los pueblos de San Cristóbal y de San Bartolomé y su única hacienda, la de Zipiapa.

Coxcatlán era el segundo partido en importancia. Comprendía los pueblos de San Juan Ajalpan, San Sebastián Zinacatepec, San Pedro Tetitlán, San José Miahuatlán, San Mateo y San Gabriel Chilac; las haciendas de Nopala, San José Buenavista, San Pedro, San Lucas y Tilapa; los ranchos de Ajusco, La Calavera, Tepexingo, Los Clementes, Eytepeque y Coloalco y, finalmente, ahí mismo se localizaba el trapiche de Calipan.

Otro partido importante por el número de localidades que encabeza es el de San Antonio de la Cañada; éste engloba los pueblos de San Francisco Altepexi, Santa María Nativitas, San Esteban, San Bernardino, Santa María del Monte y Santa Catarina; las haciendas de La Trinidad, Nativitas, Zabaleta y San Francisco; los ranchos de San Salvador, Matlatecoya y Cuitlaspeque.

San Martín Zapotitlán era cabecera de los pueblos de Santa Ana, los Reyes Metzontla, San Francisco de la Rinconada, San Juan Atzingo, Santiago Acatepec, San Pedro Otzumba, Caltepec y Texcala, y de los ranchos de Santa Lucía, Acatitlán, Tlacuiloltepeque, El Encinal, San Luis, San Francisco y el rancho de Agua de Mena.

Finalmente, el partido de San Pablo Zoquitlán incluía los pueblos de San Francisco Xitlama, Santa María Coyomeapa, San Juan Cuautla, Santa María Xocotla, San Miguel Eloxochitlán, Azayahualulco, Tlacotepec y Mazateopan. ${ }^{3}$

Al término del régimen colonial la jurisdicción de Tehuacán se constituyó en partido, formando uno de los 25 en que se dividió al estado de Puebla, según consta en su primera Constitución Política de 7 de diciembre de 1825. Un año después se reformó la división política del estado, agrupándose un amplio conjunto de partidos en sólo siete departamentos: Puebla, Atlixco, Matamoros, San Juan de los Llanos, Zacatlán, Tuxpan y Tepeaca; este último departamento fue el que acogió los municipios de Tehuacán, Chapulco, Tepanco, Zapotitlán, Coyomeapa, La Cañada, Coxcatlán, Eloxochitlán, San José Miahuatlán, Ajalpan, Zoquitlán y Santiago

\footnotetext{
${ }^{3}$ La enumeración de localidades probablemente no sea exhaustiva, ya que se trata de los lugares mencionados a lo largo de todo el listado de habitantes no indígenas del padrón militar de la jurisdicción de Tehuacán, hacia 1791. Algunos pueblos puramente de indios debieron ser omitidos. Véase AGN, Ramo Padrones, vol. 3, "Padrón general de familias españolas, castizas y mestizas", ff. 115-276, y "Padrón general de familias pardas y morenas", ff. 320-372.
} 
Miahuatlán (A. Commons, 1971: 65-67). Ei 16 de febrero de 1853 se desmembraron los departamentos en distritos, configurándose finalmente el distrito de Tehuacán, con terrenos del antiguo partido y otros dominios de Chalchicomula y Tecamachalco (Palacios, 1982:289).

\section{Evolución de la población en su espacio regional}

Investigaciones paleodemográficas acerca del valle de Tehuacán ponen en evidencia la relación positiva entre la evolución cultural y el crecimiento de la población en la antigüedad. A medida que se desarrollan las formas de subsistencia y las técnicas agrícolas, los pobladores se incrementan (MacNeish, 1964:37 y 1970:215250). En Tehuacán se sabe de primitivos habitantes, anteriores al 7000 a.C., que formaban microbandas trashumantes: recolectores de alimentos y cazadores menores. Posiblemente había tres microbandas de cuatro a ocho personas cada una. Richard S. MacNeish (1964) distingue ocho fases culturales: Ajuereado (10000 a 7000 a.C.), El Riego (7000-5000), Coxcatlán (5000-3400), Abejas, Purrón y Ajalpan temprano (3400-1200), Ajalpan tardío (1200-900), Santa María (900-100), Palo Blanco (100 a.C.-700 d.C.) y Venta Salada (700-1500 d.C.).

Las macrobandas sucedieron a las microbandas y los nómadas se empezaron a sedentarizar con la introducción de algunos cultivos como el chile y la calabaza, en primer lugar, y después con el frijol y el maíz. Durante la fase Abejas y Purrón, los pobladores se convierten en agricultores la mayor parte del tiempo y aparecen las primeras aldeas semipermanentes. En estos tiempos la densidad de población es de cerca de 14 personas por 100 kilómetros cuadrados. Durante los tres estadios culturales precedentes, la densidad de la población era de la mitad, de la sexta y hasta de una trigésima fracción en los tiempos más remotos.

Los agricultores comienzan la hibridación de plantas e inician trabajos de riego; al mismo tiempo afilian sus aldeas ceremonialmente (Ajalpan tardío y Santa María). Las ciudades sagradas y las aldeas agregadas ceremonial y políticamente son asentamientos propios de agricultores con técnicas de riego más depuradas (Palo Blanco) y, finalmente, cuando la producción agrícola se diversifica y se especializa, al mismo tiempo que el comercio adquiere una mayor amplitud, las ciudades y aldeas - con centros ceremoniales propios - forman sistemas de comunidades afiliadas económica, política y religiosamente (Venta Salada). La densidad de población para estos momentos previos a la conquista es de 4166 indi- 
CUADRO 1

Evolución de la población tributaria de la jurisdicción de Tehuacán, 1521-1743

\begin{tabular}{lc}
\hline Año & Población \\
\hline 1519 & 20000 (jefes de familia) $^{*}$ \\
1570 & 6430 tributarios \\
1600 & 4400 tributarios \\
1629 & 1670 tributarios \\
1696 & 4380 tributarios \\
1743 & 4832 (familias de indios) \\
\hline
\end{tabular}
de jefes.

viduos por 100 kilómetros cuadrados; cuatro veces más que en los años circundantes al inicio de nuestra era y 25 más que en el primer milenio anterior a ésta. El área ocupada por la cultura de Venta Salada significa $90 \%$ del territorio poblado en los tiempos históricos; es decir, después de la llegada de los conquistadores. Su población, en términos absolutos, sería de alrededor de 87000 individuos.

La cifra estimada por MacNeish (1964) no se apartaría mucho de otra que podemos avanzar mediante un juego de suposiciones. De acuerdo con fray Toribio de Benavente, ${ }^{4}$ la provincia de Tlaxcala contaba con un millón de indios en los albores de la conquista. Si suponemos gruesamente que la jurisdicción de Tehuacán guardaba la misma proporción de habitantes que aquella de fines del siglo XVIII con respecto al total de la intendencia (8\%), entonces habría supuestamente unos 80000 pobladores.

A partir de la conquista, la población indígena experimentó un descenso catastrófico, a causa principalmente de enfermedades epidémicas portadas por los españoles contra las cuales los aborígenes estaban biológicamente desprotegidos. Las cifras que aparecen a continuación, proporcionadas por Peter Gerhard (1972:262), se refieren exclusivamente a población indígena tributaria, pero iluminan la evolución de la población total desde los primeros tiempos coloniales. Al igual que en el resto de la Nueva España, en Tehuacán se experimentó un derrumbe durante el siglo XVI y durante la primera mitad del siglo siguiente; dándose una intensa recuperación demográfica a partir de las décadas centrales del mismo XVIr. Esto último es un caso poco común en el México central y, dada la magnitud de dicho resarcimiento, habrá que

${ }^{4}$ Fray Toribio de Benavente (1914: 105), citado por Sherburne F. Cook y Lesley B. Simpson (1948: 20). 
atribuirlo a una fuerte inmigración, más que a la propia reposición natural de sus habitantes, cuyas mujeres - de cualquie: manera- debieron mantener niveles de fecundidad elevados.

Hacia la última década del siglo XVIII, el territorio de Tehuacán estaba poblado por cerca de 42000 personas. El indígena dominaba el paisaje étnico aportando $87 \%$ del total de almas, con 36300 efectivos (véase Vicente Nieto, 1791). La población blanca que se instaló desde sus orígenes, así como la población negra que fue transportada fundamentalmente a la tierra caliente del partido de Coxcatlán -incluido el trapiche de Calipan - representan, al lado del sector mestizo, producto de la unión de los tres grandes troncos étnicos presentes, el $13 \%$ restante de la población global para este periodo. Los mestizos y castizos, los pardos, los criollos y los europeos sumaban, entonces, 5456 habitantes en toda la jurisdicción. Éstos se repartían en los siete partidos que conformaban su territorio. La ciudad de Tehuacán acogía la mitad de esta población no indígena, el partido de Coxcatlán la secundaba con $31 \%$ y la quinta parte restante se repartía, por orden de importancia, entre Zapotitlán, Chapulco, Tepanco, La Cañada y Zoquitlán (véase cuadro 2). Españoles y mestizos eran los más numerosos, cada uno de estos grupos significaba un tercio del total (los espanoles, sin embargo, superaban ligeramente al grupo mestizo). Los pardos rebasaban ligeramente una cuarta parte del grupo (se trata de una proporción elevada de gente de color si se compara con la conformación étnica que presentan la mayoría de los poblados alejados del mar, y explica además los rasgos fenotíoicos de la población actual del sur del distrito). Finalmente, los castizos (a media distancia entre el criollo y el mestizo) arañaban la décima parte del grupo no indígena de la jurisdicción.

Tehuacán de las Granadas:

Su perfil sociodemográfico a fines del virreinato

De acuerdo con los datos que ofrecen los únicos padrones militares de la intendencia de Puebla que llegaron a nuestros días ${ }^{5}$ y que forman parte de la serie de listados levantados entre 1790 y 1794 en la Nueva España, según ordenanza del virrey conde de Revillagigedo, se sabe que a una gran distancia de la capital de la

5 ACN, Ramo Padrones, vols. 3, 7, 25, 27 y 38 (resúmenes generales de población). Véanse también las cifras dadas por Hugo Castro Aranda, en Secretaría de Programación y Presupuesto (DCE) (1977: 64, 65 y 67). Estas fuentes son la base de los datos proporcionados en el mapa de la intendencia de Puebla. 


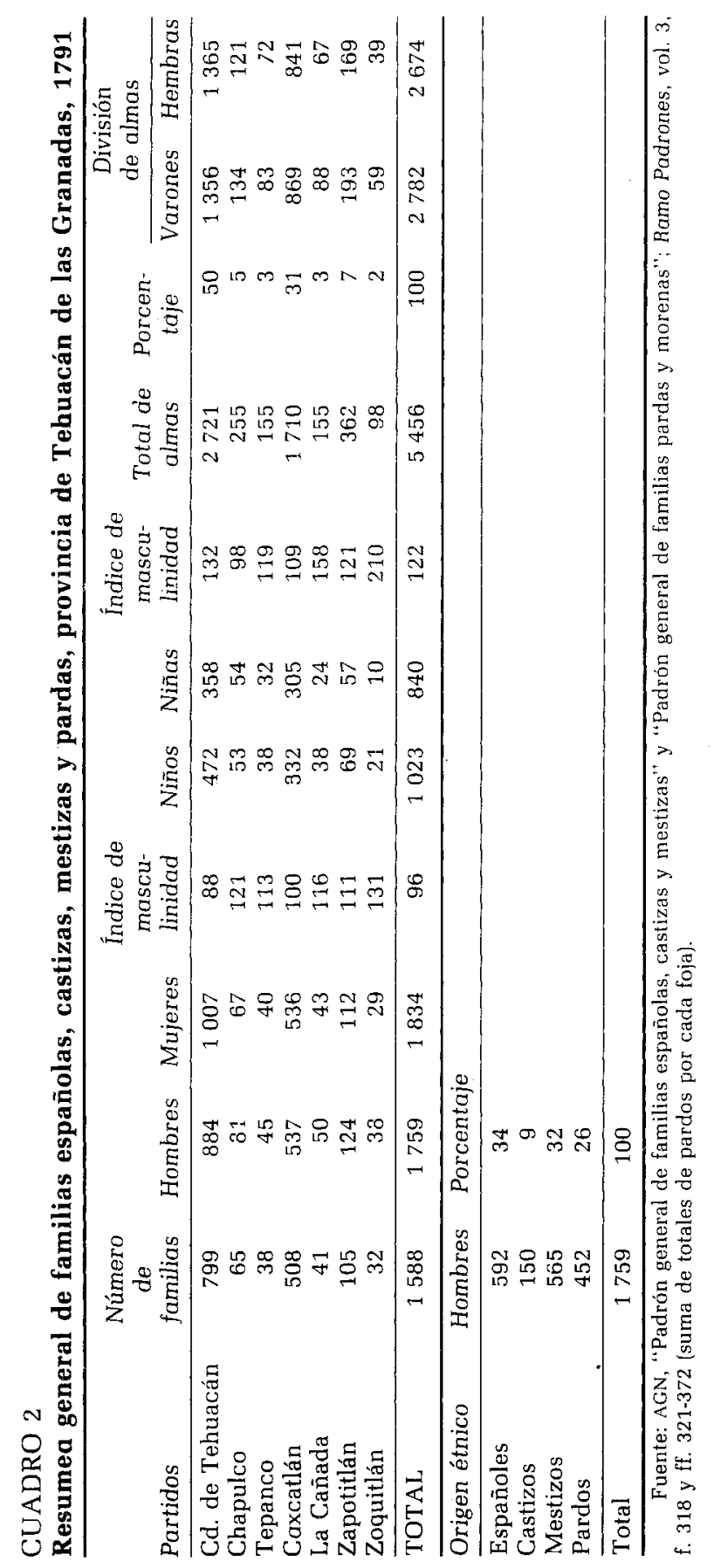


intendencia -en términos demográficos- cuatro son las ciudades o villas más importantes del territorio: Teziutlán (2 848 almas de españoles y mestizos), Atlixco ( 2444$)$, Tehuacán (2 358) y Tepeaca (2 237). La ciudad de las Granadas se levanta como el núcleo urbano más importante del sureste de la intendencia, siendo considerada como una ciudad de primera categoría por lo que respecta a los ingresos que proporcionaban sus tributos y contribución del medio real. ${ }^{6}$ Otras poblaciones que le seguían en importancia eran Huejotzingo, Izúcar, Tlapa y San Juan de los Llanos (véase mapa). Hay que hacer notar que el orden de importancia dado con anterioridad se refiere exclusivamente a población española y mestiza (sin incluir a la población negroide), ya que los padrones militares recababan információn sobre estas personas en listados separados de los pardos. Excluido de la milicia, así como por razones fiscales, el indio se registra por separado en las matrículas de tributarios.

La población de la ciudad de Tehuacán de las Granadas y su partido en las postrimerías del régimen colonial se describe en el padrón militar de la provincia, ejecutado por don Vicente Nieto y datado en Orizaba el 28 de septiembre de 1791. El censo está integrado por un padrón general de familias españolas, castizas y mestizas, y por un listado reservado a las familias de pardos y morenos levantado, igualmente que el anterior, por partido y en cada una de sus localidades. ${ }^{7}$ En vista de que ambos listados se formaron por domicilios y calles - o por número progresivo de familias en barrios y localidades rústicas - se logró acoplar familias y hogares mixtos. El apareamiento se verificó con nombres y apellidos, etnias, estados y ocupaciones. La elaboración de un solo listado continuo, desde la Plaza Mayor hasta la última localidad rústica, permitió analizar el tamaño real de las unidades domésticas.

Para 1791, el teniente en jefe del regimiento provincial de Córdoba y Jalapa, don Vicente Nieto, atestigua que la población asciende a 5505 almas de españoles, indios y demás castas; su tamaño equivale, por lo tanto, a cerca de una décima parte de la ciudad de Puebla. Debido a la omisión de indígenas en la lista de habitantes señalada con anterioridad, el universo de estudio se limitará

6 "General noticia de todas las jurisdicciones de esta Nueva España, temperamentos, frutos y obispados, tributos y tributarios (1784)", en Enrique Florescano e Isabel Gil (1973: 11-39).

${ }^{7}$ La información que se analizó para el presente estudio es solamente la relativa al partido de Tehuacán de las Granadas, de ambos padrones. Véase fuente en nota 3: ff. 115-219 y ff. 320-333 (el foliado original indica ff. 1-53 y ff. 1-7, respectivamente). 
a los españoles y sus mezclas con el indio y el negro. Esta porción de población asciende a 2725 personas de ambos sexos y de todas las edades. ${ }^{8}$

El empadronamiento de la población se efectuó a partir del "circuito de la Plaza Mayor", abarcando las cuadras de la traza urbana, luego los barrios circundantes y, finalmente, las haciendas, molinos, ranchos y pueblos aledaños. Se registran 20 calles, entre las que destacan por su tamaño - tanto desde el punto de vista del número de domicilios como de sus moradores-en orden descendente, la Calle Real (tramo del camino real entre México y Oaxaca, con destino a Guatemala), la primera del Quartel o del Mesón, la de las Damas, la del Molino, la del Refugio, la de la Pedrera, la segunda del Quartel, la del Calvario, la del Gicotal, la de la Targea y la del Humilladero. Entre las más pequeñas se anotan los cinco callejones que serpentean las manzanas: el del Curato, de la Bóveda, del Cabildo, del Carmen y el callejón del Susto (véase cuadro 3). Las calles de mayor prestigio son las que rodean la Plaza Mayor, la Calle Real, la del Mesón, la de las Damas, la del Molino y los callejones del Curato y de la Bóveda. En ellas residen los administradores y oficiales reales, los presbíteros, los curas y sus tenientes, los funcionarios eclesiásticos, los escribanos públicos, los comerciantes y los hacendados. Las calles eminentemente comerciales son la vía Real y la del Molino, ya que concentran carca de la mitad de los comerciantes y sus cajeros, a los cuales se agregan un buen número de tratantes; estos últimos, por cierto, se ubican singularmente en el callejón del Carmen y en la calle del Humilladero. Otras calles que destacan por concentrar algunos oficios preferentes son el mismo callejón del Carmen, que alberga junto con sus tratantes a una tercera parte de los carpinteros tehuacanenses, dando como resultado que tres cuartas partes de los hogares de la callejuela sean de tratantes y carpinteros. El $35 \%$ de los sastres habita en las calles de la Targea, en la misma avenida Real y en la Calle de las Damas; en. esta última se agrupa también una cuarta parte de los tejedores de la ciudad.

En el sector urbano central hay una alta tasa de desocupación (18\%): de 419 domicilios censados, 77 se encuentran vacíos. Las calles que registran los valores más altos son la del Calvario y el

${ }^{*}$ Al comparar esta cifra con el total de almas que avanza el cuadro 2 para la ciudad de Tehuacán. se constata una diferencia de cuatro individuos, que fueron listados pero no enumerados en el cuadro sumario original. En adelante, el universo que será analizado abarcará 2776 personas; ya que se retuvieron para el análisis 51 indios, de ambos sexos, que fueron empadronados debido a los lazos de parentesco o de servidumbre que guardaban con los otros grupos étnicos. 
callejón del Cabildo (dos de cinco domicilios), en la segunda del Quartel se detecta $27 \%$ de desocupación, un domicilio vacío por cada cuatro se sucede en la calle de las Damas, y en las extensas vías de la Pedrera, del Refugio, del Molino y en la Real se encuentran desocupados un poco más de la quinta parte. Los domicilios ocupados al menos por un hogar albergan hogares adicionales a razón de 116 por 100 domicilios. A grandes rasgos se observa que a medida que se aleja uno de las calles centrales y de mayor prestigio, el índice de concentración de hogares adicionales en torno al hogar domiciliario aumenta. El tamaño promedio de los hogares urbanos es de cuatro miembros -cifra típica para la época-, que traduce el hecho de que a pesar de las altas tasas de fecundidad "natural" de las tehuacanenses, su dimensión se regula por el elevado nivel de la mortalidad y en razón de la nupcialidad precoz a la cual sigue la creación de un nuevo hogar. A lo anterior se agrega el efecto de una estrechez económica que imposibilita el mantenimiento de hogares extensos.

En el caso de los barrios, haciendas y pueblos, se tomaron en cuenta exclusivamente familias o núcleos conyugales separados, así como hogares de personas solas; a diferencia de la zona urbana en donde la información permitía el análisis de hogares, es decir, unidades en las que podrían cohabitar diferentes núcleos conyugales. El tamaño de la familia en este sector es de 3.3 miembros, cifra que se apega aún más a la explicación dada con anterioridad. La ciudad está rodeada por seis barrios: el de Tulà, del Carmen, de la Pedrera, de San Juan de Dios, de Apantle Grande y el de Tlacolcalco. El barrio de mayor tamaño es el de San Juan de Dios, que junto con los de la Pedrera y de Tula abarcan un poco más de $80 \%$ de la población suburbana (véase cuadro 3). En estos tres barrios se concentran las dos terceras partes de los panaderos de Tehuacán y, en el caso de los dos primeros, destaca también la concentración en ellos de prácticamente la totalidad de los veleros y matanceros del partido. Asimismo, es interesante mencionar que los únicos sastres y carpinteros detectados en el conjunto de los barrios fueron localizados en los de San Juan y la Pedrera, ubicándose también, en este último, un tercio del total de los zapateros.

En las haciendas, molinos y pueblos habita $13 \%$ de los feligreses blancos y negroides de la parroquia del Sagrario de Tehuacán. Las haciendas que pertenecen a su jurisdicción - tal como se acotó con anterioridad-son la de San Lorenzo, El Riego, El Húmilladero, Santa Cruz, La Huerta, San Andrés y Chapultepeque. Hay tres molinos de trigo: el Molino Chico o de San Diego, el de Santa Cruz, adjunto a la hacienda del mismo nombre, y el de Calcahualco, perteneciente a la hacienda de La Huerta. Sólo se en- 


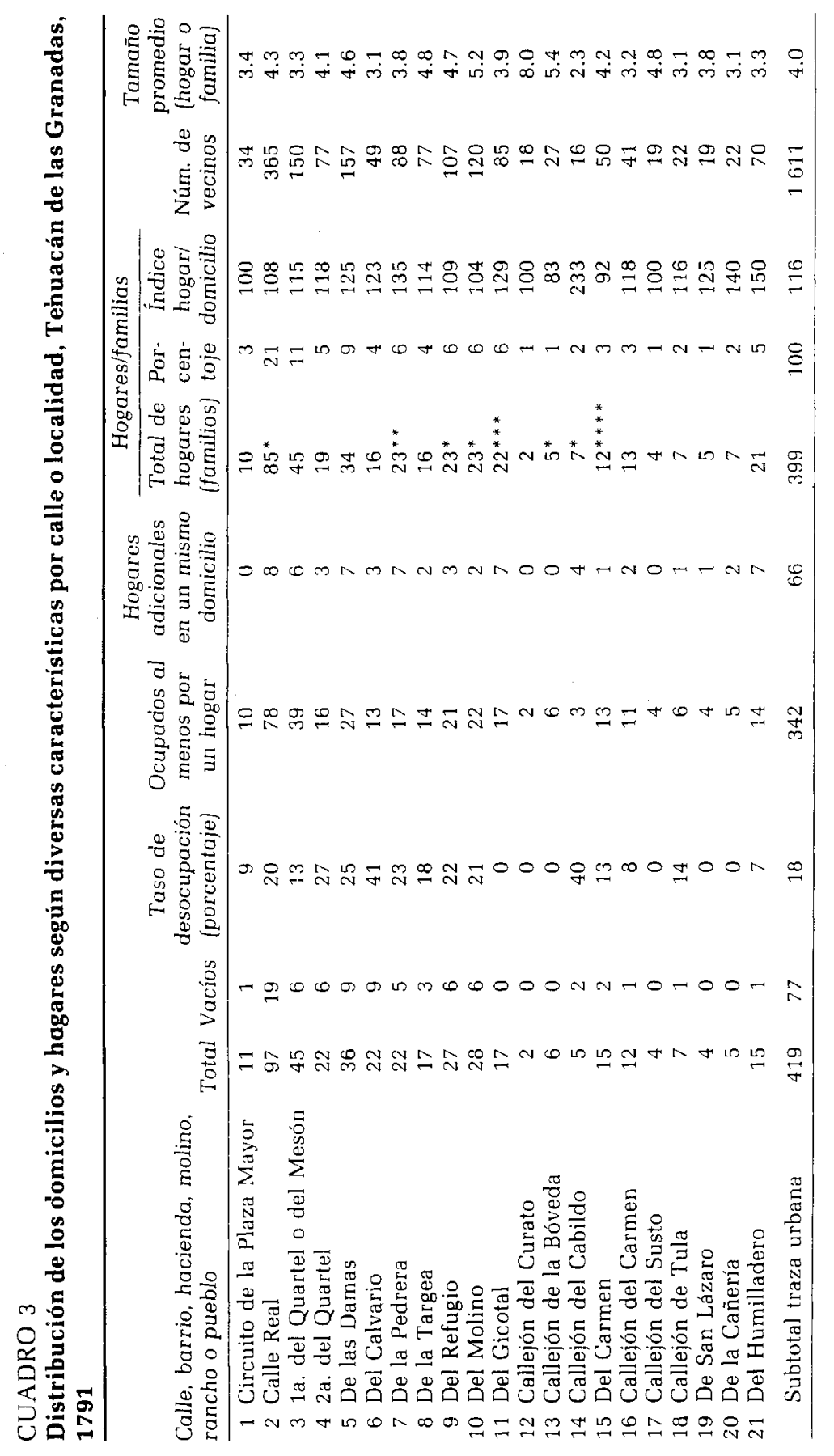




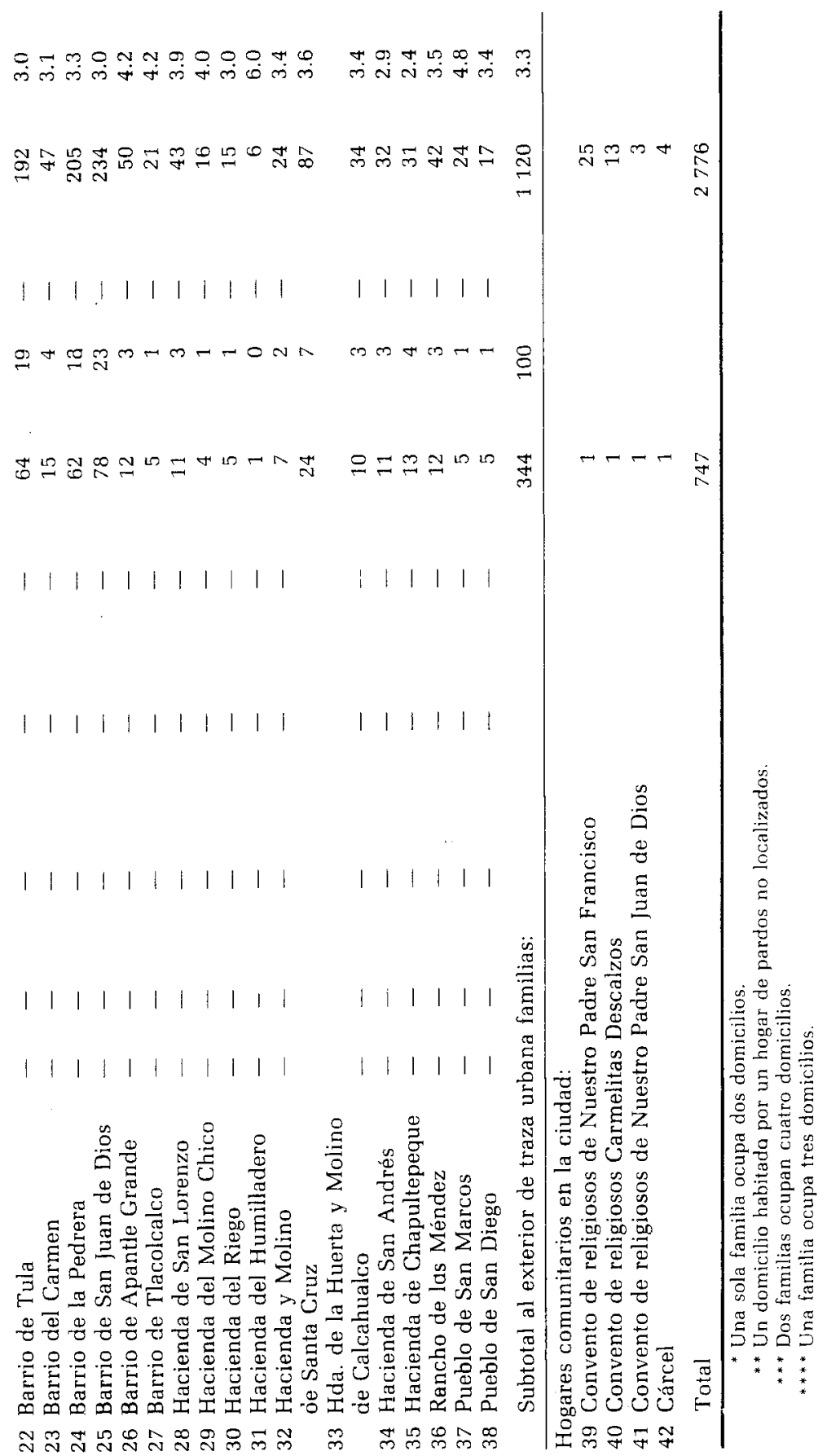


cuentra un rancho, el de Los Méndez, y dos pueblos habitados no solamente por indios: San Marcos y San Diego.

La hacienda y molino de Santa Cruz es la unidad productiva que cuenta con el mayor número de pobladores no indígenas -111 personas - que significan la tercera parte de los habitantes de las nueve fincas; su tamaño es comparable con el de la población de los tres barrios pequeños de Tehuacán en su conjunto: El Carmen, Apantle Grande y Tlacolcalco. De los moradores de Santa Cruz, casi cuatro quintas partes se enlistan como habitantes del molino, lo que sugiere, en primer lugar, la orientación preferente de mano de obra no-indígena a la molienda y, enseguida, el número de empleados y sus familias dan fe de la importancia que tuvo la producción de harinas, cuya comercialización debió además facilitarse por su feliz ubicación a la vera del camino real. De acuerdo con el número de pobladores, a esta última localidad rústica seguían la hacienda de San Lorenzo y el rancho de Los Méndez; en un nivel intermedio se situaban La Huerta, San Andrés y Chapultepeque, y finalmente las unidades más pequeñas eran el Molino Chico, la hacienda del Riego y la del Humilladero. En términos de población blanca, mestiza y negroide, los pueblos de San Marcos y San Diego muestran una cantidad insignificante.

En la ciudad se ubican cuatro hogares comunitarios: los conventos de religiosos franciscanos, de carmelitas descalzos y de padres juaninos, a los cuales se agrega la cárcel del poblado. El convento de Nuestro Padre San Francisco, "de orden toscano, pero bien distribuido", recoge el mayor número de miembros: 25 frailes; el del Carmen, con una comunidad de la mitad de la franciscana (13 religiosos), ocupa un edificio "moderno [y] . . bien trabajado, pues su templo con claustros, y demás oficinas es de lo mejor del Reyno; y San Juan de Dios [apenas con su prior, un fraile y la cocinera]. . . está en el más infeliz estado, como su Hospital, cuya situación y asistencia es detestable. La enfermería no tiene la menor ventilación, y sus aires corrompidos, y mefíticos exalan pestilenciales efluvios, capazes de agravar la más simple enfermedad, y hacerla mortífera o incurable" (véase Vicente Nieto, 1791:ff. 44v.). En la cárcel están recluidos tres españoles: un operario preso por indicios de robo, un joven labrador de Tlacotepec que "lo ha puesto su padre por incorregible" y un labrador de 46 años de edad, oriundo de Salamanca, que es reo por muerte. A éste lo acompaña su esposa en la prisión.

En virtud del carácter militar del padrón de Tehuacán, éste adolece de imprecisiones serias por lo que respecta a la edad de la población en su conjunto; sólo se acota la edad de los hombres de 13 años en adelante, y se hace a un lado a todas las mujeres y 
CUADRO 4

Distribución de la población total según el sexo, grupos decenales de edad y el estado matrimonial, Tehuacán de las Granadas, 1791

\begin{tabular}{|c|c|c|c|c|c|c|c|c|c|c|c|c|}
\hline \multirow{3}{*}{$\begin{array}{l}\text { Grupos de } \\
\text { edad }\end{array}$} & \multicolumn{6}{|c|}{ Estado matrimonial } & \multirow{2}{*}{\multicolumn{2}{|c|}{$\begin{array}{l}\text { No de- } \\
\text { clarado } \\
\end{array}$}} & \multicolumn{4}{|c|}{ Total } \\
\hline & \multicolumn{2}{|c|}{ Casados } & \multicolumn{2}{|c|}{ Viudos* } & \multicolumn{2}{|c|}{ Solteros } & & & & Porcen- & & Porcen- \\
\hline & $H$ & $M$ & $H$ & $M$ & $H$ & M & $H$ & $M$ & $H$ & taje & $M$ & taje \\
\hline $13-14$ & 0 & 0 & 0 & 0 & 7 & 0 & 30 & 0 & 37 & 3 & 0 & 0 \\
\hline $15-24$ & 40 & 0 & 2 & 0 & 74 & 0 & 129 & 0 & 245 & 18 & 0 & 0 \\
\hline $25-34$ & 153 & 0 & 6 & 0 & 38 & 0 & 25 & 0 & 222 & 16 & 0 & 0 \\
\hline 35.44 & 139 & 0 & 5 & 0 & 16 & 0 & 7 & 0 & 167 & 12 & 0 & 0 \\
\hline $45-54$ & 79 & 0 & 15 & 2 & 16 & 1 & 1 & 0 & 111 & 8 & 3 & 0 \\
\hline $55-64$ & 37 & 0 & 15 & 0 & 10 & 1 & 1 & 0 & 63 & 5 & 1 & 0 \\
\hline 65 y más & 20 & 0 & 7 & 0 & 5 & 0 & 0 & 0 & 32 & 2 & 0 & 0 \\
\hline Niños** & 0 & 0 & 0 & 0 & 0 & 0 & 464 & 354 & 464 & 34 & 354 & 25 \\
\hline Adultos & 23 & 491 & 2 & 191 & 3 & 348 & 3 & 16 & 31 & 2 & 1046 & 75 \\
\hline Tolal & 491 & 491 & 52 & 193 & 169 & 350 & 660 & 370 & 1372 & 100 & 1404 & 100 \\
\hline
\end{tabular}

* Este grupo incluye personas que no declaran su estado matrimonial, pero se sabe qu* aún tienen hijos viviendo con ellas. También se agregaron las personas solteras con hijos do clarados. Tales casos sólo se presentan para el sexo femenino.

** Incluye al único nin̄o que declaró edad: 11 años, no declara su origen étnico ni su lugar de origen, es criado.

los niños (véase cuadro 4). A pesar de los errores y omisiones que el censo pueda presentar, es posible delinear los grandes rasgos de su estructura sociodemográfica.

El perfil de la pirámide de la población de Tehuacán denota una estructura de edades jóvenes, que obedece a una fecundidad elevada a través de los años (véase gráfica 1); $37.3 \%$ de la población masculina tiene menos de 15 años, no obstante, este grupo debió haber tenido una mayor representatividad, ya que es notorio el ocultamiento de los jóvenes de 13 y 14 años de edad que "prometían" para el servicio militar. La población adulta intermedia significa $55.5 \%$ y la tercera edad (mayores de 55 años) representa $7.1 \%$. Las mujeres se encuentran ligeramente sobrerrepresentadas a razón de mil mujeres por 977 hombres. Esta relación debió ser en realidad más marcada, ya que el índice de masculinidad entre los niños menores de 13 años es sumamente alto (131.0), lo que hace evidente una subenumeración importante de párvulas. En el caso del sexo femenino, se puede mencionar que de las mujeres registradas una cuarta parte son niñas y las otras tres restantes son adultas.

En Tehuacán había 491 parejas, o sea $35.8 \%$ de la población masculina estaba en unión, así como $35.0 \%$ de la femenina. La viudez alcanza mayores proporciones entre el sexo femenino, puesto que cerca de una quinta parte de las mujeres adultas ha 


\section{GRÁFICA 1}

\section{Población según el sexo, la edad y el estado matrimonial} Tehuacán de las Granadas, 1791

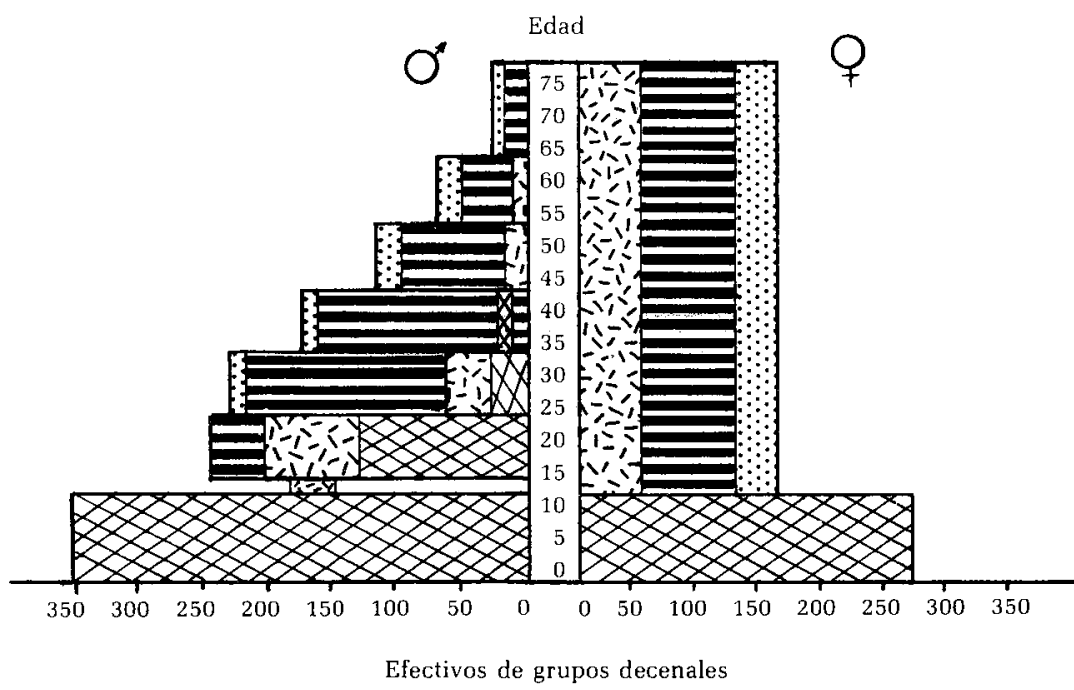

$\therefore$ Viudos

Fuente: cuadro 3.

perdido a su marido. Dada la menor mortalidad del sexo femenino a medida que avanza la edad y a la nupcialidad en segunda y tercera ocasión más frecuente entre los hombres, sólo se advierte un porcentaje de viudos menor a $6 \%$. El estado de celibato, en cambio, era más importante entre los hombres, ya que tres quintas partes se declaran solteros o sin estado, en tanto que las mujeres doncellas apenas sobrepasan la mitad de su grupo. Si por un lado para el empadronador la edad de las mujeres no era significativa, su estado matrimonial era muy importante: casi no hay mujer cuyo estado no haya sido especificado: casada, viuda o doncella. Por el contrario, 193 hombres no lo declaran -fuera de los niños-, aunque debido a su joven edad y a su situación dentro de los hogares es muy probable que hayan sido solteros. Asumiendo esta hipótesis, la proporción de solteros con respecto al total por grupos de edad arroja una edad media masculina al primer matrimonio de 25.2 años. Se trata de una edad tardía para la época, aunque cercana al modelo nupcial de la población española de un barrio de la ciudad de Puebla (Grajales Porras, 1982:104-105); en efecto, de haber- 
se registrado a los indios - cuya nupcialidad es más precoz- la edad media al primer matrimonio se hubiese ubicado en un rango sensiblemente menor, más acorde con otros parámetros registrados en algunas poblaciones coloniales. Los españoles, mestizos y mulatos tehuacanenses se desposaban tardíamente y un grupo importante (15\%) nunca buscó pareja o bien no logró encontrar a la mujer adecuada.

La ciudad de las Granadas, sus barrios y haciendas circunvecinas continúan siendo altamente indígenas a fines del régimen colonial: prácticamente la mitad de su población es de indios. A diferencia de la ciudad de Puebla y de la villa de Atlixco - cuya traza original se proyectó para habitación de labradores, comerciantes y artesanos españoles- el origen de Tehuacán cabe recordar que es el de un asentamiento eminentemente indígena, que con el tiempo fue núcleo de atracción de población blanca y negroide, así como escenario de mestizaje. En 1791, esta cara de la población tehuacanense adquiere diversos tintes (véase cuadro 5): una de cada dos mujeres son mestizas o castizas, casi dos entre cinco son españolas criollas y sólo una de cada ocho mujeres es mulata o parda. Los hombres de color (14\%) también se encuentran en minoría dentro de la ciudad ante el grupo mestizo y el criollo, que significan cuatro quintas partes de la población no indígena; ambos grupos se encuentran casi igualmente representados, con una ligera ventaja numérica para mestizos y castizos.

Los habitantes de origen europeo son los menos numerosos; sólo se mencionan dos mujeres y 60 hombres provenientes del Viejo Mundo (5\%). A estos últimos se agregaba un solitario iımigrante nativo de La Habana. No obstante su número tan reducido, la ciudad de Tehuacán resultaba para ellos muy sugestiva. Desmesuradamente, era casi tan importante el número de inmigrantes de ultramar $-46 \%$ del total de los no-nativos de la ciudad- que los que se aproximaban del mismo territorio americano. En términos absolutos, en Tehuacán había más europeos que en cualquier poblado de las provincias e intendencias del norte del virreinato, de Tlaxcala, de la misma villa de Carrión en el valle de Atlixco, e incluso más que en tres parroquias de la ciudad de Puebla reunidas: Analco, la Santa Cruz y San Sebastián. De cada mil individuos no indígenas 23 habitantes son europeos. Esta relación se acerca a la de la Ciudad de México y rebasa definitivamente a la proporción de inmigrantes ibéricos que se hallan en ciudades tales como Guadalajara, Durango, Mérida, Tlaxcala y Atlixco. Esta atracción se debe atribuir, sin duda, a que Tehuacán mantenía una intensa actividad comercial en tanto que punto de enlace entre Puebla, Veracruz y Oaxaca; recordemos, asimismo, que se conside- 


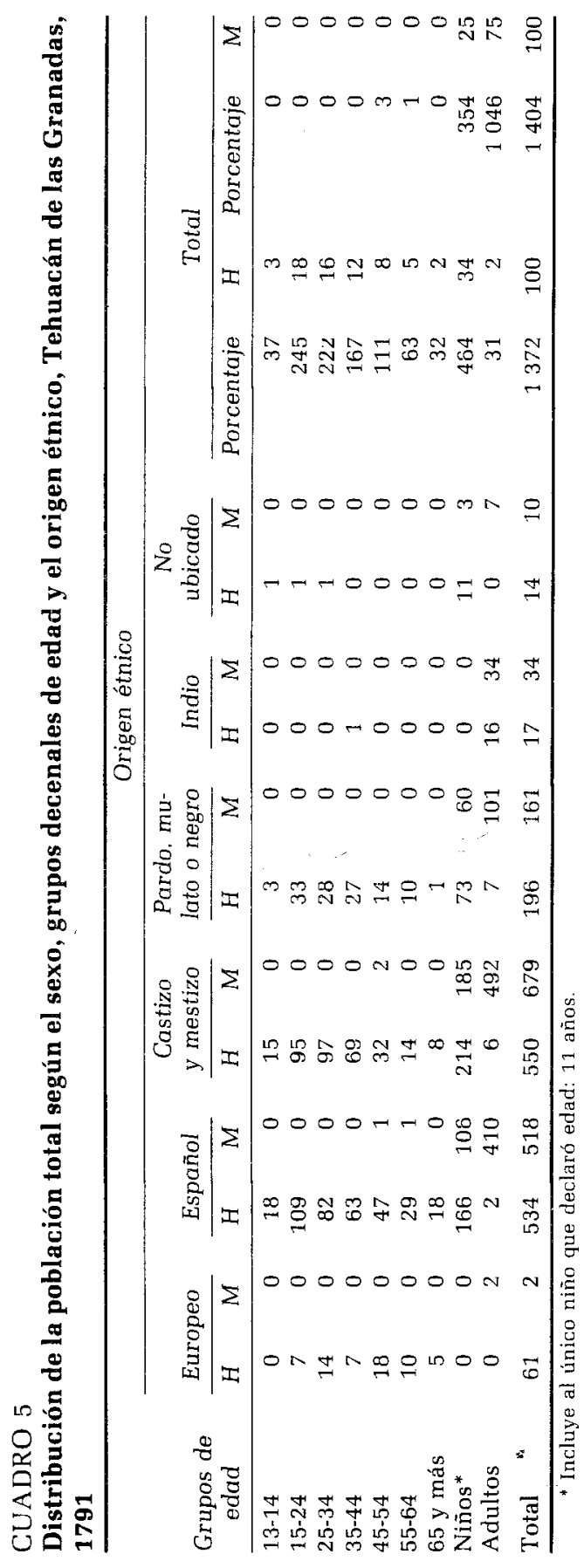


raba como una ciudad de primera categoría por su recaudación; por otro lado, la administración de las diversas empresas reales, reservada a los súbditos que se estimaban más nobles y leales, resultaban lucrativas, y finalmente hay que mencionar los conventos que albergaban un número considerable de religiosos que habían profesado en conventos peninsulares.

De 1372 varones registrados entre niños y adultos, 837 declaran un oficio, una posición o bien algún impedimento físico para el trabajo. Las oportunidades de empleo en el partido eran amplísimas. Casi la totalidad de los varones, desde los muchachos de 13 años hasta los ancianos - sin mediar en ellos ninguna diferencia significativa en cuanto a su edad-se hallaban involucrados en la producción de bienes y en los servicios. Las tasas de participación en el trabajo se ubicaban por encima de 95\% - en promedio-y sólo los ancianos de más de 65 años disminuían su participación, al observarse un desempleo de $12 \%$. El trabajo femenino, al igual que en todo el mundo de la época, era menospreciado y nada digno de aparecer en una enumeración de los ejercicios masculinos.

Las actividades de los moradores eran fundamentalmente primarias, ya que $40 \%$ de los hombres activos se desempeñaba en la agricultura. Un tercio se dedicaba a proporcionar servicios y una cuarta parte se insertaba en el sector manufacturero. Las actividades preponderantes - después de la labranza- eran el comercio y los transportes, representados por 38 tratantes, 14 comerciantes y sus 17 cajeros aprendices; además de 44 arrieros, quienes secundaban en número a los 270 labradores. La industria del vestido y la confección ocupaba tres sombrereros, un solo botonero y 42 sastres, los cuales se ubicaban como el tercer gremio más numeroso de la ciudad (42\%). Los productores de alimentos - panaderos, molineros y matanceros - satisfacían a bastanza las necesidades del consumo interno. Los servicios domésticos, netamente proporcionados por gente de color y mestizos, eran altamente demandados. Los servicios eclesiásticos en el partido eran atendidos por 15 clérigos del orden secular: el cura y juez eclesiástico, licenciado don José Pizarro de los Reyes y don Bernardo de la Vega, cura de la ciudad. Ambos estaban auxiliados por ocho presbíteros, a los que se agregaban cuatro ordenados de menores y un catedrático de vísperas. El culto religioso, igualmente estimado, lo desempeñaban 27 miembros del clero regular; los tres priores de los conventos - Ignacio de Alcorta, de los franciscanos; Francisco de Santa Anna, de los carmelitas, y Pedro Abreu, de los juaninosestaban a la cabeza de religiosos, frailes coristas (profesos) y hermanos legos o donados. Todas las actividades que se han mencio- 
nado hasta ahora eran los sectores cruciales en la vida ordinaria del partido de Tehuacán, toda vez que ocupaban a tres cuartas partes de sus hombres en activo. Carpintería, tejeduría, zapatería, herrería, albañilería y cohetería eran otros ejercicios de importancia entre los tehuacanenses.

En la ciudad residían don Nicolás Quilty de Valois, juez y subdelegado de la ciudad y partido sujeto al intendente de Puebla don Manuel de Flon y Tejada; don Basilio Manas, administrador de alcabalas, tabacos y naipes (que reconoce a la intendencia de Veracruz); don Manuel de Herrera y Tagle, alguacil mayor del Santo Oficio; don José Domínguez, colector de diezmos; don Carlos Álvarez de Echeverría, escribano real y público, y don Manuel de Prenda, notario público; don Félix José Ponce, administrador de la renta de correos; don Ignacio José de Larrasquito, capitán de comercio, y cinco "hijodalgos": don Pedro José Ceballos, don Pedro Ignacio de Otamendi, don Juan Cosme del Castillo y don José de Meza, padre e hijo. Estos últimos eran también terratenientes, al igual que las familias de Argarate, Medrano, Ferrón, Apezechea, Martínez y, la más destacada de todas por el número de sus propiedades, la Del Moral. Asimismo, habitaban militares de diversos regimientos y el cirujano del provincial de Tres Villas; escribientes, estudiantes, doradores y plateros, barberos, un músico, un escultor, un profesor examinado en medicina y una maestra de primeras letras.

La población blanca y sus allegados mestizos y mulatos se distinguían del indio -entre otras características de índole social, económica y legal- por el uso de un apellido que acompañaba al nombre de pila. En el padrón se asientan no sólo los nombres y apellidos de los hombres adultos, sino también de las mujeres. El caudal de apellidos que porta la población actual de Tehuacán debe encontrar forzosamente sus orígenes desde los primeros tiempos coloniales. El censo provee, ya para fines del XVIII, un vasto patrimonio de apellidos españoles que identifican indistintamente tanto a criollos como a mestizos y mulatos. Es muy probable que incluso una porción pequeña de indios haya comenzado a usar estos apellidos. Se enlistan 403 apellidos diferentes para 1167 individuos, dando como resultado un número promedio de casi tres individuos que se apellidan igual; no obstante, un poco más de la mitad de los que declaran su nombre completo usan un apellido único. Lo anterior hace evidente la variedad de los apelativos y su alto poder discriminante con fines de identificación.

A pesar de la heterogeneidad de los patronímicos, había algunos que resultaban ser más frecuentes; a fines del virreinato, los Méndez eran los más numerosos y, junto con los Rodríguez, los 
García, los Arizmendi y los González denominaban a una décima parte de la población. Un grupo mayor de apellidos: Clemente, Moreno, Sánchez, Bravo, Flores, Ramírez, Gómez, Huerta, Ramos y Trujillo se sumaban para identificar a otra proporción igual de moradores.

La conformación del territorio y la evolución social y económica de la población de Tehuacán han delineado al Tehuacán contemporáneo. La posición estratégica en la red de caminos coloniales y su función como eje comercial interno permanecen, ya que se erige aún como el centro político y económico más importante en el sur del estado. La configuración de su actual estructura económica tiene sus raíces en los tiempos novohispanos; de lo anterior dan fe las ocupaciones descritas, así como otras ausentes en las estadísticas que se manejaron y que también fueron relevantes en el conjunto de las actividades productivas de la región, mismas que describe, en 1806, el conde de la Cadena, don Manuel de Flon, en su Descripción de la Intendencia de Puebla, en los siguientes términos:

... Hay cuatro molinos... y tres trapiches de hacer azúcar en que se beneficiaron el año pasado de 1802, 1500 arrobas de ellas, 15000 porrones de miel y 100000 mancuernas de panela piloncillo. Los principales frutos de aquellas haciendas consisten en maíz de que se cosecharon en el mismo año pasado 20000 cargas, en trigo que ascendió a 1800 , en cebada que llegaría a 1000 cargas, en frijol, que no pasó de 400 y en chile de varias calidades que llegaría a 1000 arrobas, y también en la cría y engorda de ganado cabrío de que se mataron en el año de 1805, 35000 cabezas, cuyo producto de sebo y carne después de abastecida aquella jurisdicción sale para Puebla, Veracruz y Oaxaca ... la subsistencia de los indios consiste por lo común en el tráfico y expendio del petate que fabrican y venden en el mismo partido, en las villas de Orizava y Córdova, y en los mercados de Veracruz, y Puebla... (Citado por A. Commons, 1971:59-60.)

\section{Bibliografía}

Archivo General de la Nación (AGN), Ramo Padrones, vols. 3, 7, 25, 27 y 38. Benavente, fray Toribio de (1914), Historia de los indios de la Nueva España, Barcelona, Ed. D.S. García.

Castro Aranda, Hugo (1977), Primer censo de población de la Nueva España, 1790: Censo de Revillagigedo, "un censo condenado", México, Secretaría de Programación y Presupuesto (DGE).

Commons de la Rosa, Aurea (1971), Geohistoria de las divisiones territo- 
riales del estado de Puebla, México, Instituto de Geografía, Unam. Cook, Sherburne F. y Lesley B. Simpson (1948), The population of Central Mexico in the Sixteenth Century, Berkeley y Los Angeles, University of California Press, Iberoamericana, núm. 31.

Florescano, Enrique e Isabel Gil (1973), Descripciones económicas generales de Nueva España, 1784-1817, México, SEP-INAH.

Gerhard, Peter (1972), A guide to the historical geography of New Spain, Cambridge, Cambridge University Press, Latin American Studies: 14.

Grajales Porras, Agustín (1982), Exploitation démographique d'un dénombrement mexicain ancien, tesis de maestría en demografía en la Universidad Católica de Lovaina.

MacNeish, Richard S. (1964), El origen de la civilización mesoamericana visto desde Tehuacán, México, Departamento de Prehistoria, INAH. (1970), "Social implications of changes in population and settlement pattern of the 12000 years of Prehistory in the Tehuacan Valley of Mexico", en Paul Deprez (comp.), Population and economics (trabajos presentados en el Cuarto Congreso de la Asociación Internacional de Historia Económica, 1968, llevado a cabo en la Universidad de Indiana, en Bloomington], Winnipeg, University of Manitoba Press, pp. 215-250.

Nieto, Vicente (1791], "Descripción de la provincia de Tehuacán de las Granadas", fechada en Orizaba el 28 de septiembre, en el Padrón Militar de Tehuacán, Archivo General de la Nación-México (AGN), Ramo Padrones, vol. 3, ff. 1-13.

Palacios, Enrique Juan (1982], Puebla: su territorio y sus habitantes, tomo 1, Puebla, Junta de Mejoramiento Moral, Cívico y Material del Municipio de Puebla. 